\title{
PERENCANAAN SISTEM DRAINASE DAN TROTOAR (STUDY KASUS : LINGKUNGAN KELURAHAN BANJARAN KOTA KEDIRI)
}

\author{
${ }^{1}$ Romadhon, ${ }^{2}$ Moch Zaenuri, ${ }^{3}$ Herlan Pratikno \\ ${ }^{1,2,3}$ Fakultas Teknik Universitas Kadiri \\ E-mail : romadhon@unik-kediri.ac.id,zaeunuri_arifin@unik-kediri.ac.id, \\ herlan_pratikto@unik-kediri.ac.id
}

\begin{abstract}
The data used to plan the drainage is a complete situation map with the topography used to plan the flow direction. Furthermore, rainfall data from three stations for 20 years were then tested for consistency, homogeneity test. Furthermore, the discharge is calculated based on the average rain height with the rational method $Q=0.2778 \times C \times I \times A$. Then cumulative discharge (rainwater discharge + citizen wastewater discharge) is planned for the drainage channel. From the cumulative discharge, the channel dimensions are calculated using Manning's formulation. From the situation map and topographic data obtained the type of channel size and after calculated with the Manning formula obtained square dimensions, namely: $b=0.80 \mathrm{~m}$ and $h=0.10 \mathrm{~m}$. In addition, a guard height of $0.70 \mathrm{~m}$ was also obtained, then from that dimension the Cost Budget Plan (RAB) was calculated as Rp. 2,929,983,000.00 After the survey and planned, the sidewalk design uses $1.10 \mathrm{~m}$ width width and $0.20 \mathrm{~m}$ sidewalk height. Using cover material U-Ditch Cover coated with 20x40 Andhesite stone, 30x30 disabled Tegel Line for pedestrians with disabilities, brush / ampyang stones for $70 \times 70$ Manhole Iron binder.
\end{abstract}

Keywords: Drainage System, Water Discharge, Calculation Method

\section{ABSTRACT}

Data yang digunakan untuk merencanakan drainase ini adalah peta situasi lengkap dengan topografinya yang digunakan untuk merencanakan arah aliran. Selanjutnya data curah hujan dari tiga stasiun selama 20 tahun yang kemudian diuji konsistensi, uji homogenitas. Selanjutnya dihitung debit berdasarkan tinggi hujan rata-rata dengan metode rasional $Q=0,2778 \times C \times I \times$ A.Kemudian dihitung debit Komulatif (Debit air hujan + debit air limbah warga) untuk rencana saluran drainase. Dari debit Komulatif kemudian dihitung dimensi salurannya dengan formulas Manning. Dari data peta situasi dan topografi didapatkan tipe ukuran saluran dan setelah dihitung dengan formula Manning didapat dimensi persegi, yaitu : $b=0.80 \mathrm{~m}$ dan $h=0,10 \mathrm{~m}$. Selain itu juga didapatkan tinggi jagaan $0.70 \mathrm{~m}$, kemudian dari dimensi tersebut dihitung Rencana Anggaran Biaya (RAB) sebesar Rp. 2.929.983.000,00 Setelah survey dan direncana, desain trotoar menggunakan lebar dimensi $1.10 \mathrm{~m}$ dan tinggi trotoar $0.20 \mathrm{~m}$. Menggunakan bahan penutup Cover U-Ditch dilapisi batu Andhesit 20x40, Tegel Line difabel 30x30 untuk pejalan kaki disabilitas, batu sikat / ampyang untuk pengikat Manhole Iron $70 x 70$.

Kata Kunci : Sistem Drainase, Debit Air, Metode Perhitungan 


\section{PENDAHULUAN}

\subsection{Latar Belakang}

Kelurahan Banjaran adalah sebuah Kelurahan di Kecamatan Kota yang berada di tengah Kota Kediri. Kota Kediri memiliki luas $63,40 \mathrm{~km}^{2}$ terbelah oleh sungai Brantas yang membujur dari selatan ke utara sepanjang 7 kilometer.Secara administratif, Kelurahan Banjaran di kelilingi beberapa Kecamatan yaitu sebelah barat Kecamatan Mojoroto, sebelah timur Kecamatan Pesantren, sebelah utara kecamatan Ngasem. Sejalan dengan meningkatnya laju pertambahan penduduk di Kelurahan Banjaran yang cukup tinggi, menyebabkan buangan air limbah tidak terpakai semakin besar pula. Pertumbuhan penduduk yang tidak diimbangi dengan saluran drainase yang memadai menimbulkan permasalahan drainase di Kelurahan Banjaran.

Kelurahan Banjaran terindikasi bila Intensitas curah hujan tinggi, saluran drainase exsisting tidak mampu menguras/membuangan kelebihan air yang tidak diinginkan, sehingga menimbulkan bajir tahunan dan bau limbah yang menyengat dikarnakan trotoar yang rusak. Oleh sebab itu perlu dilakukan perencanaan saluran drainase dan trotoar yang memenuhi kebutuhan dari debit air yang akan lewat saluran di lokasi Kelurahan Banjaran Kota Kediri.

Dengan adanya perencanaan sistem saluran drainase dan trotoar yang baik, ekonomis dan sesuai kebutuhan pada wilayah Kelurahan Banjaran Kecamatan Kota, maka diharapkan aliran air hujan dan air limbah yang akan masuk saluran dapat mengalir dengan lancar dalam ruang atau dimensi dari saluran drainase yang dibangun berdasarkan data-data perhitungan yang telah didapatkan.

\subsection{Rumusan Masalah}

Pada perencanakan sistem drainase permukiman Kelurahan Banjaran. Adapun permasalahan dalam perencanaan saluran drainase ini adalah :

1. Berapa tinggi debit hujan yang menjadi debit banjir?

2. Berapa debit limbah dari rumah tangga yang harus ditampung saluran drainase?

3. Bagaimana dimensi saluran drainase?

4. Berapa Rencana Anggaran Biaya (RAB) pembangunannya?

5. Bagaimana desain trotoar penutup saluran drainase?

\section{METODE PENELITIAN}

\subsection{Curah Hujan Rancangan}


Curah hujan rancangan adalah analisis berulangnya suatu peristiwa baik frekuensi persatuan waktu maupun kala ulangnya. Cara yang digunakan dalam menentukan curah hujan rancangan ini adalah :

\subsection{Metode Gumbel}

Menurut Gumbel (1941), persoalan yang berhubungan dengan harga-harga ekstrim adalah datang dari masalah banjir. Tujuan dariteori statistik harga rata-rata ekstrim adalah untuk menganalisa hasil pengamatan harga-harga ekstrim tersebut untuk meramal harga ekstrim berikutnya. Untuk menghitung debit air hujan dalam mendimensi saluran drainase digunkan metode Rasional. Dalam daerah perkotaan yang kecil, kehilangan air boleh dikatakan sedikit dan disebabkan waktu konsentrasi yang pendek, maka debit keseimbangan seringkali dicapai. Dari alasan inilah rumus rasional masih digunakan untuk menaksir banjir dalam daerah perkotaan. (Imam Subarkah, 2000:48)

Debit air kotor adalah debit air yang berasal dari buangan aktivitas penduduk seperti mandi, cuci, dll., baik dari lingkungan rumah tangga, bangunan (fasilitas) umum atau instansi, bangunan komersial, dll. Dari kebutuhan air tiap hari tersebut diasumsikan besarnya air yang dibuang adalah $80 \%$. Debit air kotor yang dibuang :

\subsection{Gambar Rencana Kerja}

Sebelum kita melakukan / merencanakan pembangunan,seharusnya kita sedikit banyak mengetahui tentang gambar kerja (gambar bestek). Kemudian baru ditentukan bahan yang apa dipakai dan macam pekerjaan serta peralatan yang digunakan. Langkah menggambar kerja adalah pertama kali mengetahui kondisi lapangan desain yang cocok dan kemudian di gambar.

\subsection{Perhitungan Rencana Anggaran Biaya}

Rencana Anggaran Biaya atau sering disebut RAB adalah perhitungan biaya bangunan berdasarkan gambar kerja dan spesifikasi pekerjaan konstruksi yang akan dibangun, sehingga dengan adanya $\mathrm{RAB}$ dapat dijadikan acuan pelaksanaan pekerjaan nantinya. Tujuan dari perhitungan anggaran biaya adalah untuk mengestimasi biaya serta untuk mengontrol baik dari segi kualitas maupun kuantitas.

\subsection{Tujuan Penelitian}

Tujuan dari penelitian ini adalah untuk merencanakan saluran drainase dan trotoar di kelurahan Banjaran, agar aliran air hujan dan air limbah yang akan masuk saluran dapat mengalir dengan lancar dalam ruang atau dimensi dari saluran drainase yang dibangun berdasarkan data-data perhitungan yang telah didapatkan serta mendesain trotoar yang kondisi existing yang sudah rusak. Agar tidak terjadi banjir tahunan dan masyarakat tidak mencium bau limbah saluran. 


\subsection{Lokasi Penelitian}

Lokasi penelitian ini di lakukan di Jl. Slametriadi Kelurahan Banjaran Kecamatan

Kota, Kota Kediri. (Bab. 1 halaman 6) 


\subsection{Teknik Analisis Data}

Berikut ini merupakan tahapan-tahapan prosedur pelaksanaan perhitungan untuk merencanakan dan melengkapi data, yakni:

1. Data curah hujan bulanan selama sepuluh tahun terakhir yang didapatkan dari tiga stasiun curah hujan milik Pg. Pesantren, UPT Kediri, Mrican.

2. Menghitung rata-rata curah hujan rancangan menggunakan Metode Gumbel.

3. Menghitung Debit Banjir air hujan Rencana (Q) dengan Rumus Rasional Mononobe.

4. Setelah ketemu total debit air hujan + debit limbah tahap selanjutnya perhitungan rencana Dimensi saluran dengan menggunakan Rumus Manning.

5. Perencanaan gambar rencana saluran dan trotoar menggunakan aplikasi Autocad.

6. Perhitungan Rencana Anggaran biaya dengan dasar analisa dari Dinas Pekerjaan Umum Dan Penataan Ruang (PUPR).

Bagan Alir Perencanaan

Berikut ini adalah bagan alur pembahasan atau perencanaan 


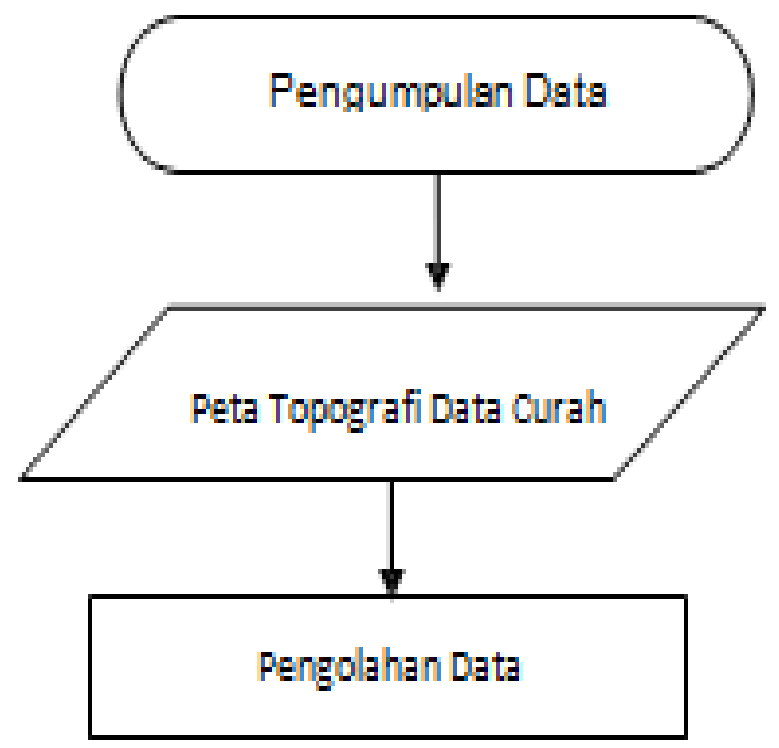

Perhitungan debit banjir rancangan

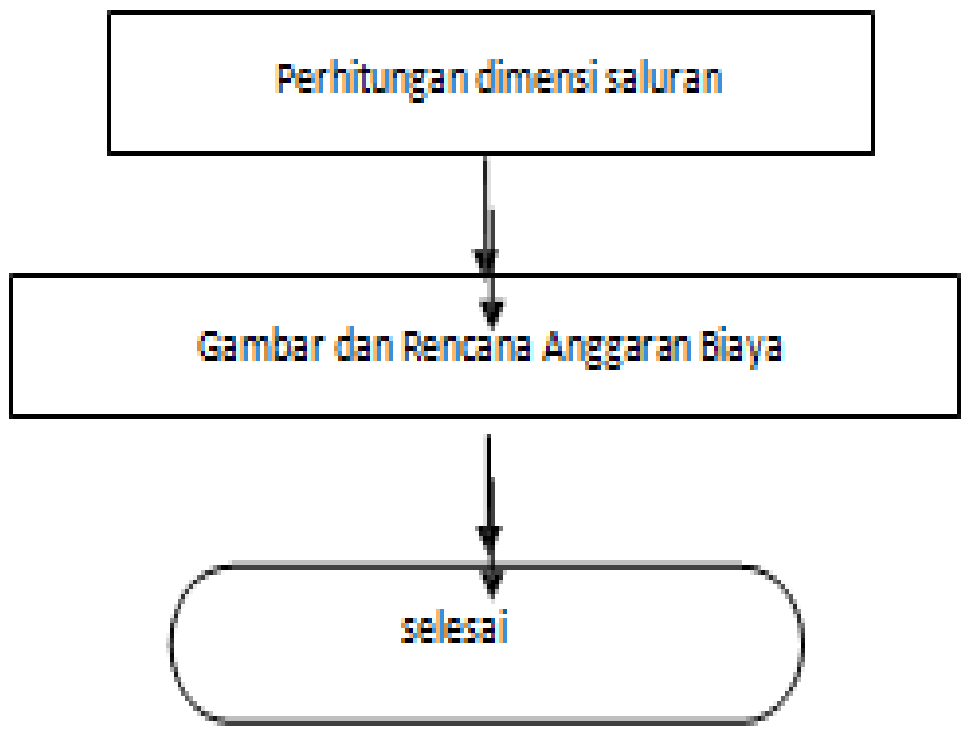




\section{HASIL DAN PEMBAHASAN}

\subsection{Hasil Perhitungan}

Hasil Analisa dan dan pembahasan pada Perencanaan Sistem Drainase Dan Trotoar(Study Kasus : Lingkungan Kelurahan Banjaran Kota Kediri) disesuaikan dengan tata cara perhitungan metode gumbel dan manning.

Hasil Perhitungan Debit Air Hujan $=0.020 \mathrm{~m} 3 / \mathrm{detik}=20$ liter/detik

Hasil Perhitungan Debit Air Kotor $=0,016 \mathrm{~m} 3 / \mathrm{detik}=16$ liter/detik

Hasil Debit Kumulatif $\quad=\quad 36$ liter/detik atau $0,036 \mathrm{~m} 3 /$ detik

\subsection{Perhitungan Dimensi Saluran}

Perhitungan dimensi saluran dipengaruhi oleh debit kumulatif yang mengalir pada saluran yang tidak boleh melebihi kecepatan ijin.

Penampang persegi

Perhitungan saluran 1-2 :

- Panjang saluran $(\mathrm{Ld})=640 \mathrm{~m}$ '

- Debit kumulatif $=0,036 \mathrm{~m} 3 /$ detik

- Angka koefisien kekasaran Manning = 0,014

- Jenis saluran mikro (lahan rumah, taman, kebun, kuburan, tak terbangun)

- Kemiringan $(\mathrm{S})=$ el awal -el akhir $-12,5-10,90 \quad-0,0025$

Ld 640

- Luas tampang saluran : A = b . h $\quad h=0,10 . b=0,80 m$ A $=0,08 \mathrm{~m} 2$

- Keliling basah : $\mathrm{P}=\mathrm{b}+2 . \mathrm{h} \quad 0,80+(2.0,10)=1,00 \mathrm{~m}$

- Radius hidrolik : $\mathrm{R}=\mathrm{A} / \mathrm{P}=0,08 / 1,00=0,08$

- Formula Manning: $=.2 / 3 . /$

$=1 / 0,014 \cdot(0,08) 2 / 3 \cdot 0,00251 / 2$

$=0,660 \mathrm{~m} 3 /$ detik

- $\mathrm{Q}=\mathrm{v} \times \mathrm{A} \quad$ Debit Banjir hitungan (m3/Detik) $\mathrm{Q}$

$=0,660.0,08$

$\mathrm{Q}=0,052 \mathrm{~m} 3 /$ Detik

- Dimensi yang dipakai $: \mathrm{b}=$

$0,80 \mathrm{~m}$

$\mathrm{h}=0,10 \mathrm{~m} \mathrm{w}=$ 
$0,70 \mathrm{~m}$

\section{KESIMPULAN DAN SARAN}

\subsection{Kesimpulan}

Setelah melalui perhitungan mengenai perencanaan drainase kota Pacitan, dapat disimpulkan bahwa :

1. Debit air hujan sudah diperoleh sebesar $0,020 \mathrm{~m} 3 /$ detik atau 20 liter/detik.

2. Debit air kotor yang masuk saluran sudah diperoleh sebesar $0,016 \mathrm{~m} 3 /$ detik, dan debit kumulatif yaitu : 0,036 m3/detik atau 36 liter/detik.

3. Dari perhitungan didapatkan dimensi dengan menggunakan saluran berbentuk persegi, dimana tinggi penampang basah $=0,10 \mathrm{~m}$ dengan tinggi jagaan air sebesar $0,70 \mathrm{~m}$ dan lebar 0,8 $\mathrm{m}$ dengan panjang $640 \mathrm{~m}$. Dimensi saluran memang dibuat lebih lebar dan tinggi untuk mengantisipasi buangan sampah dan mengendapnya walet daritahun ke tahun oleh masyarakat agar saluran tidak tersumbat dan tetap bisa mengalir.

4. Rencana Anggaran Biaya pembangunannya sebesar Rp 2.929.983.000,00

5. Dari gambar desain hasil perencanaan trotoar pada (Bab. 4 hal. 55 ) di dapat dengan dimensi lebar trotoar $1.10 \mathrm{~m}$ dengan penutup Cover U-Ditch dilapisi batu Andhesit 20x40, Tegel Line difabel 30x30 untuk pejalan kaki disabilitas, batu sikat / ampyang untuk pengikat Manhole Iron $70 \times 70$, dan tinggi trotoar $0.20 \mathrm{~m}$.

\subsection{Saran}

1. Pada proses perencanaan dan perhitungan, usahakan asumsi-asumsi yang digunakan mendekati kenyataan di lapangan dan ada referensi dari sumber ilmu;

2. Pada perencanaan saluran dibuat lurus rata-rata;

3. Pada saat penggambaran harus benar-benar memperlihatkan skala, baik skala horisontal maupun vertikal;

4. Pelaksanaan saluran drainase sebagai fasilitas umum harus didahulukan sebelum membangun rumah agar tidak terjadi banjir;

5. Dalam pelaksanaan pekerjaan di lapangan, harus memperhatikan keselamatan kerja, kualitas dan kuantitas bahan (RAB) maupun peralatan yang digunakan agar mendukung proses pekerjaan, sehingga didapat hasil kerja yang maksimal serta dapat menghemat biaya.

\section{DAFTAR PUSTAKA}


[1] [BSN] Badan Standardisasi Nasional. 1998 SNI. 03-1724-1989: Pedoman dan Perencanaan Hidrologi dan Hidrolik untuk Bangunan Sungai

[2] [BSN] Badan Standardisasi Nasional 1994. SNI. 03-3424-1994: Tata Cara Perencanaan Drainase Permukaan Jalan.

[3] [BSN] Badan Standardisasi Nasional 1991. SNI. 03-2406-1991: Tata Cara Perencanaan Umum Drainase Perkotaan

[4] Anggrahini, Ir., Hidrolika Saluran Terbuka. Citra Media, Surabaya : 2007. Dinas Pekerjaan Umum Dan Penataan Ruang. Analisa Harga Satuan. Kediri : 2018.

[ 5 ] Halim Hasmar HA., Ir., MT., Drainase Perkotaan. UII Press, Yogyakarta : 2004.

[6] SNI 03-3424-1994. Tata Cara Perencanaan Drainase Permukaan Jalan.

[7] Soemarto CD., Ir., B.I.E.Dipl. H., Hidrologi Teknik. Usaha Nasional, Surabaya : 2007 Sofyan M. Noerbambang. Perancangan \& Pemeliharaan Sistem Plumbing.

[8] Suripin, Dr., Ir., M.Eng. Sistem Drainase Perkotaan yang Berkelanjutan. Andi, Yogyakarta : 2004

[9] Santoso, E. B. (2008). Studi Perencanaan Penataan Kawasan Alun-alun Kota Brebes. Jurnal Teknik Sipil dan Perencanaan, 10(2), 151-160.

[10] Santoso, E. B. (2008). Studi Perencanaan Penataan Kawasan Alun-alun Kota Brebes. Jurnal Teknik Sipil dan Perencanaan, 10(2), 151-160.

[11] Sri, P. R. W., Suripin, S., Soebroto, S., Muhrozi, M., \& Bagus, H. S. (2015, August). Sistem Drainase Pada Jalan Pantura; Permasalahan dan Alternatif Solusi. In Seminar nasional teknik jalan ke-3 (Vol. 3, pp. 8-1). HPJI. 